\title{
High Temperature Tensile Deformation Behavior and Failure Mechanisms of an Al-Si-Cu-Mg Cast Alloy - The Microstructural Scale Effect
}

\author{
Mohammadreza Zamani, Salem Seifeddine, Anders E.W. Jarfors \\ Jönköping University; School of Engineering, Department of Materials and Manufacturing - Casting, \\ P.O. Box 1026, SE-551 11, Jönköping, Sweden \\ E-mail: mohammadreza.zamani@jth.hj.se
}

\begin{abstract}
In this study the high temperature tensile deformation behavior of a commercial Al-Si-Cu-Mg cast alloy was investigated. The alloy was cast with two different cooling rates resulted in average secondary dendrite arm spacing of 10 and $25 \mu \mathrm{m}$, which are typical of the microstructure scale obtained from high pressure die casting and gravity die casting. Tensile tests were performed at different strain rates $\left(10^{-4} \mathrm{~s}^{-1}\right.$ to $\left.10^{-1} \mathrm{~s}^{-1}\right)$ and over a wide temperature range from ambient temperature to $500{ }^{\circ} \mathrm{C}$. The fine microstructure had superior tensile strength and ductility compared to the coarse microstructure at any given temperature. The coarse microstructure showed brittle fracture up to $300{ }^{\circ} \mathrm{C}$; the fracture mode in the fine microstructure was fully ductile above $200^{\circ} \mathrm{C}$. The fraction of damaged particles was increased by raising the temperature and/or by microstructure coarsening. Cracks arising from damaged particles in the coarse microstructure were linked in a transgranular-dominated fashion even at $500^{\circ} \mathrm{C}$. However, in the fine microstructure alloy the inter-dendritic fracture path was more prevalent. When the temperature was raised to $300^{\circ} \mathrm{C}$, the concentration of alloying elements in the dendrites changed. The dissolution rates of $\mathrm{Cu}$ - and $\mathrm{Mg}$-bearing phases were higher in the fine microstructure.
\end{abstract}

Keywords: EN AC-46000 cast alloy, elevated temperatures, deformation behavior, coarseness of microstructure

\section{Introduction}

Research on Al-Si based casting alloys has been re-focused as a lightweight structural material for automobile applications, because of their superior specific strength, encouraging mechanical properties, cost-efficient manufacturing and easy recyclability. The $\mathrm{Si}$ addition promotes castabilty and enhances strength, and $\mathrm{Cu}$ and $\mathrm{Mg}$ are commonly added to improve strength at room and elevated temperatures. Fe additions are made to reduce the die soldering tendency [1]. The microstructure of these alloys contains $\alpha$-Al dendrites as the main constituents, which are decorated with eutectic $\mathrm{Si}$ particles and many intermetallic phases such as $\mathrm{Al}_{2} \mathrm{Cu}, \mathrm{Mg}_{2} \mathrm{Si}$ and various Fe-bearing phases. Depending on the geometry of the die cast components, the cooling rates vary with the local thickness of the component. This leads to variations in the scale of as-cast microstructural features such as Secondary Dendrite Arm Spacing (SDAS) and the size and morphology of second phase particles. A high cooling rate results in a low SDAS while a lower cooling rate yields a higher SDAS. This affects the plastic deformation behavior and mechanical properties of the castings, which are affected significantly by the scale of the microstructure [2].

The solute level $(\mathrm{Mg}, \mathrm{Cu}$ and $\mathrm{Si})$, quantity and type of precipitates significantly influence the hardening rate of aluminum alloys [3-5]. Si precipitates from the as-cast super saturated solid solution during aging at temperatures range of 200-250 ${ }^{\circ} \mathrm{C}[6]$. High temperature exposure of Al-Si-Cu-Mg alloys may lead to changes in the concentrations of alloying elements and of vacancies in solid solution, and to spheroidization of Si particles [7]. The dissolution rate of the various secondary phases is dependent on time and temperature of the exposure, the chemical composition and coarseness of the microstructure.

Unlike many engineering components of Al-Si-Cu-Mg alloys which are designed to be loaded within their elastic range, in several applications, particularly motor components working at elevated temperatures such as cylinder blocks, cylinder heads, pistons and valve lifters, the alloy undergoes plastic deformation. The plastic deformation can occur at different rates of strain depending on service temperature, exposure time and magnitude of the applied load [8]. The influence of strain rate (SR) has been widely studied in wrought materials in order to optimize production rate and processing 
temperature during thermo-mechanical processing. Unlike wrought aluminum alloys, experimental data on the effect of strain rate on the deformation behavior of Al-Si based cast alloys is limited.

The effect of SDAS, size and morphology of various microstructural constituents on the tensile properties of Al-Si-CuMg alloys has been thoroughly studied at room temperature [9-12]. Rincon et al. [13, 14] investigated the tensile and deformation behavior of A319 die cast alloy, in both as-cast and heat treated conditions at elevated temperatures up to 400 ${ }^{\circ} \mathrm{C}$. Several researchers studied the effect of trace element additions on the strength improvement of Al-Si-Cu-Mg [15-18], Al-Si-Mg [19], Al-Si-Cu [20] and Al-Si alloys [21] at elevated temperatures. However an understanding of the role of cooling rate, which determines the scale of various microstructural features, on the high temperature behavior of $\mathrm{Al}-\mathrm{Si}$ based casting alloys is still lacking. Most published works on Al-Si-Cu-Mg casting alloys have been focused on the room temperature tensile properties. As yet, the role of strengthening mechanisms at elevated temperature has not thoroughly been considered in these alloys. In addition, it is expected that at elevated temperature, the scale of microstructure and strain rate will influence the mechanical behaviour and failure mechanisms. The objective of this work is therefore to study the tensile behaviour, microstructural evolution and failure mechanisms of EN AC-46000 (a typical Al-Si-Cu-Mg casting alloy) by investigating the effect of temperature, microstructural scale and strain rate.

\section{Experimental procedures}

\subsection{Materials}

The material used was EN AC-46000 aluminum alloy, containing (in wt. \%) $10.0 \mathrm{Si}, 2.6 \mathrm{Cu}, 0.24 \mathrm{Mg}, 0.8 \mathrm{Fe}, 0.8 \mathrm{Zn}$ and $0.26 \mathrm{Mn}$. Ingots of the alloy were melted in a $10 \mathrm{~kW}$ resistance furnace at $730^{\circ} \mathrm{C}$ in a silicon carbide bonded graphite crucible. Cylindrical rods (length $20 \mathrm{~cm}$, diameter $1 \mathrm{~cm}$ ) were cast in a permanent copper mold with a thin graphite coating. The cast rods were then re-melted and heated to $710^{\circ} \mathrm{C}$ for 20 minutes under Ar-atmosphere and subsequently solidified using the gradient solidification technique [2]. The gradient solidification set-up enables the production of well-fed and homogenous samples, with low levels of oxides, solidification shrinkage and gas-porosity over the entire length of the sample. The pulling rate of the furnace was used to control the scale of the microstructure and defect-free samples were produced with a microstructure scale similar to high pressure die casting (HPDC) and gravity die casting. The pulling rate of the furnace was set to 3 and $0.3 \mathrm{mms}^{-1}$, which leads to average SDAS of 10 and $25 \mu \mathrm{m}$, respectively.

\subsection{Tensile testing}

Cylindrical tensile test bars according to ASTM B557M-10 [22] of $6 \mathrm{~mm}$ in diameter and $100 \mathrm{~mm}$ in length were prepared by machining the as-cast rods. Tensile tests were carried out using a Zwick/Roell Z100 tensile testing machine, at six different temperatures ranging from $25^{\circ} \mathrm{C}$ to $500^{\circ} \mathrm{C}$. Four strain rates in the range from $10^{-4}$ to $10^{-1}$ were used. The highest strain rate, $10^{-1}$, was selected due to the intrinsic limited ductility of the alloy, especially at temperature below $0.5 \mathrm{~T}$. The lowest strain rate, $10^{-4}$, was selected to avoid creep-like deformation of the alloy. A wide test temperature range from room temperature up to slightly below the solidus temperature was chosen to allow using the experimental date to define a deformation behavior model of the alloy in a separate work. Stress-strain curves, the maximum stress value $\left(\mathrm{R}_{\mathrm{m}}\right)$, the stress at $0.2 \%$ offset strain $\left(\mathrm{R}_{\mathrm{p} 0.2}\right)$ and the strain at which failure occurs $\left(\varepsilon_{\mathrm{F}}\right)$ were obtained from the data acquisition system of the machine. In order to have statistical significance in the results, at least four replicates for each case were performed. Prior to tensile testing, the specimens were heated to the pre-set temperature and held for 15 minutes to homogenize.

\subsection{Microstructural analysis}

The microstructures and fracture surfaces were studied using optical microscopy, (OLYMPUS GX71) and a scanning electron microscope (SEM, JEOL7001F) equipped with an energy dispersive spectrometer (EDS). In order to study concentration profiles and micro segregation of the alloy elements $(\mathrm{Mg}, \mathrm{Cu}$ and $\mathrm{Si}$ ) across the dendrite arms, an SEM equipped with wavelength dispersive X-ray spectroscopy (WDS) was employed. The WDS samples were heated to given temperatures, held for $15 \mathrm{~min}$. and quenched immediately in $40{ }^{\circ} \mathrm{C}$ water. Three analysis points were measured across a single dendrite arm, and at least nine dendrites were measured for each sample. Image analysis was used for qualitative study of microstructure evolution at elevated temperature. In order to study the evolution of microstructural features at 
elevated temperatures a region in the center of a prepared specimen was identified by micro-indentation. The specimen was then heated to temperatures in the range from 300 to $500^{\circ} \mathrm{C}$, held for 15 minutes and studied after each heating without any additional surface preparation. Grain size determination was made through electron backscattering diffraction analysis to (i) ensure that there were no texture effects from the sample manufacturing, and (ii) to measure size of the grains. In order to characterize the failure mechanisms, the broken tensile specimens were mounted with the exposed cross-section parallel to the tensile axis and ground and polished to expose the center of the cylindrical bar. The fraction of fractured particles was examined by optical microscopy and quantitatively assessed using the Stream Motion image analyzer. A rectangular area $5 \times 1 \mathrm{~mm}$ on both sides of the fractured surface, (not closer than $0.1 \mathrm{~mm}$ to the fracture surface) was measured. No attempt was made in the quantitative analysis to distinguish the type, size and orientation of fractured particles. Differential scanning calorimeter (DSC) analyses were carried out in a purified argon atmosphere using a NETZSCH $404 \mathrm{C}$ Pegasus ${ }^{\circledR}$ instrument with the scanning rate of $5^{\circ} \mathrm{C} / \mathrm{min}$ in order to study any non-equilibrium reactions which may occur during heating.

\section{Results and discussion}

\subsection{Microstructural characterization}

\subsubsection{The scale and morphology of microstructural features}

Figure 1 shows the microstructural features of the EN AC-46000 alloy as-cast at two different cooling rates. The cooling rate governs size, morphology and distribution of the eutectic Si particles and intermetallic compounds [23, 24]. The microstructure consists of primary $\alpha-\mathrm{Al}$ dendrites surrounded by eutectic Si particles and intermetallic phases. The intermetallic phases identified $\left(\mathrm{Al}_{2} \mathrm{Cu}, \alpha-\mathrm{Al}_{8} \mathrm{Fe}_{2} \mathrm{Si}, \beta-\mathrm{Al}_{5} \mathrm{FeSi}\right)$ are indicated in Figure 1, which illustrates the effect of cooling rate on the scale of the microstructure. Increasing the solidification rate refines all microstructural features, decreases the SDAS and changes the morphology of eutectic silicon from large and elongated plates to small and rounder particles. This is supported by quantitative measurements of eutectic particle aspect ratio, see Table 1.
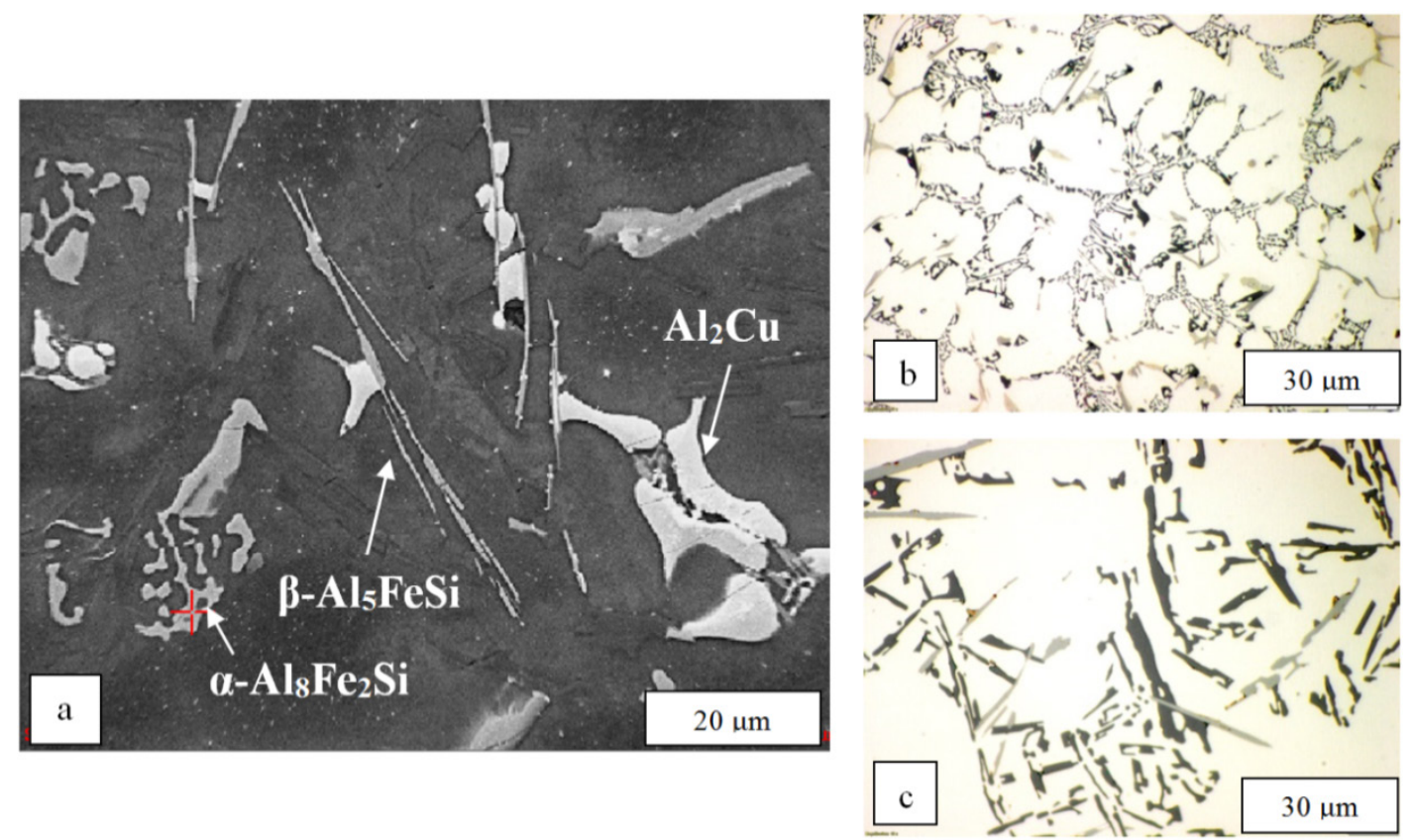

Figure 1. a) Intermetallic phases in as-cast microstructure identified through EDS analysis. Optical photomicrograph showing the effect of cooling rate on the SDAS, size, shape and distribution of eutectic Si in the alloy; b) SDAS 10 $\mu \mathrm{m}, \mathrm{c}) \operatorname{SDAS} 25 \mu \mathrm{m}$ 
Table 1. Size and morphology of the microstructural features for high and low cooling rates.

\begin{tabular}{cccccc}
\hline $\begin{array}{c}\text { Furnace pulling } \\
\text { rate }(\mathrm{mm} / \mathrm{s})\end{array}$ & $\begin{array}{c}\text { SDAS } \\
(\mu \mathrm{m})\end{array}$ & $\begin{array}{c}\text { Grain Size } \\
(\mathrm{mm})\end{array}$ & $\begin{array}{c}\text { Si particles, } \\
\text { aspect ratio }\end{array}$ & $\begin{array}{c}\mathrm{Al}_{2} \mathrm{Cu}, \text { area } \\
\text { fraction }(\%)\end{array}$ & $\begin{array}{c}\mathrm{Al}_{5} \mathrm{FeSi} \text {, length of } \\
\text { largest needle }(\mu \mathrm{m})\end{array}$ \\
\hline 0.3 & $25.9 \pm 3.4$ & $2.10 \pm 0.36$ & $3.91 \pm 0.69$ & $1.9 \pm 0.5$ & 76 \\
3 & $10.1 \pm 2.3$ & $1.19 \pm 0.28$ & $1.73 \pm 0.25$ & $2.1 \pm 0.3$ & 18 \\
\hline
\end{tabular}

\subsubsection{Cu- and Mg-bearing phases}

The change in microstructure after heat treatment (15 mins.) at various temperatures for both cooling rates is shown in Figure 2. It can be seen that increasing the temperature results in dissolution of the $\mathrm{Cu}$-containing particles ( $\operatorname{mostly~} \mathrm{Al}_{2} \mathrm{Cu}$ ) formed during solidification. A final polishing step using colloidal silica (OP-S) was used to enhance the Cu-bearing phases, turning their color to one that is readily detectable.

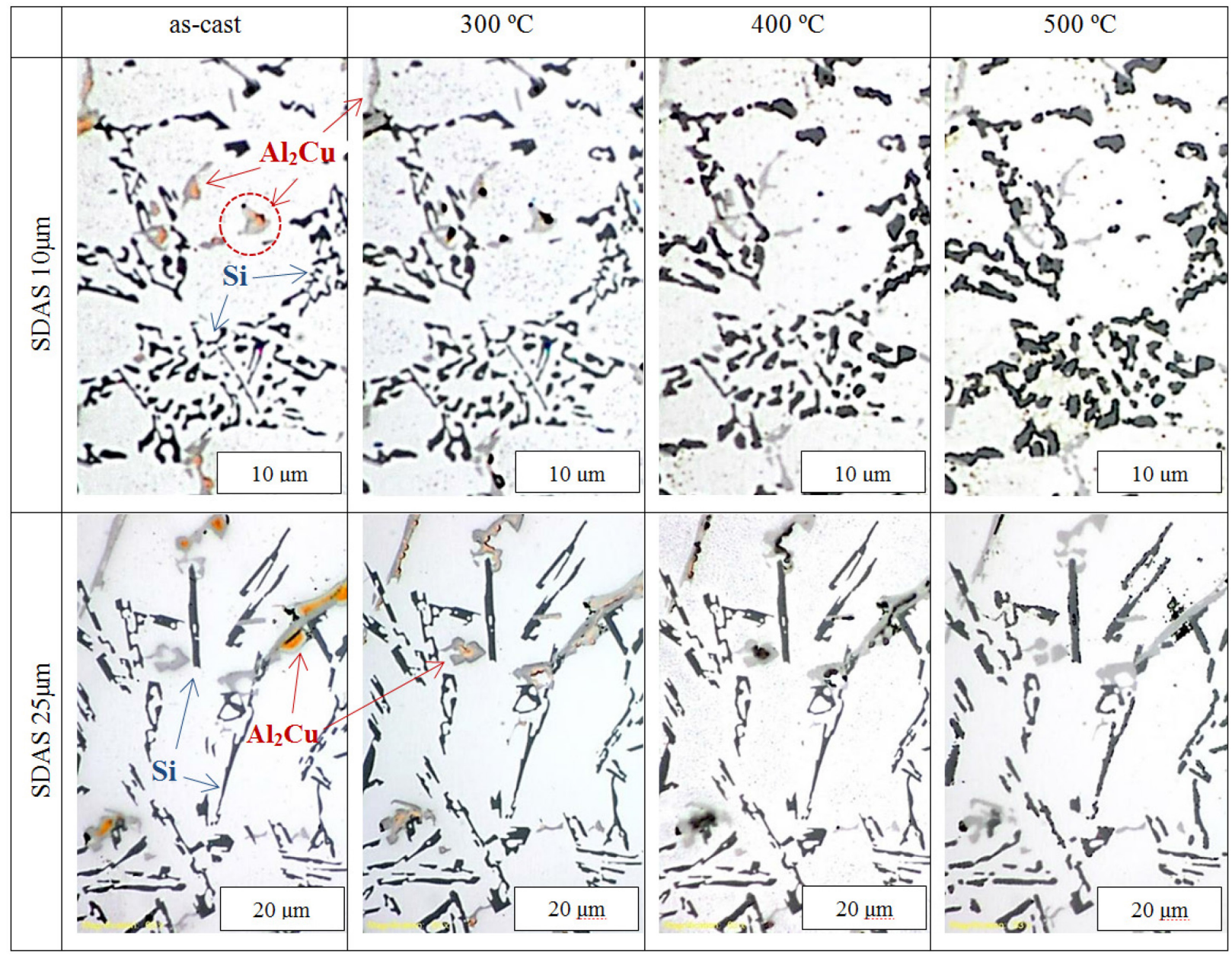

Figure 2. Micrographs after heat treatment at various temperatures for fine (SDAS $10 \mu \mathrm{m}$ ) and coarse (SDAS $25 \mu \mathrm{m}$ ) microstructures.

$\mathrm{Al}_{2} \mathrm{Cu}$ particles indicated in the $10 \mu \mathrm{m}$ SDAS samples are completely dissolved after heating to $400{ }^{\circ} \mathrm{C}$. In the as-cast condition, the $\mathrm{Al}_{2} \mathrm{Cu}$ phase is present in the form of both a eutectic phase and a block-like phase. It has been reported that the former dissolves by fragmentation to smaller segments and eventually dissolves by radial diffusion of $\mathrm{Cu}$ in the matrix, the latter however dissolves by spheroidization and shrinkage without fragmentation [25]. These two types of 
$\mathrm{Al}_{2} \mathrm{Cu}$ phase are indicated in the coarse microstructure, Figure 2. In order to understand the dissolution of $(\mathrm{Cu}-$ and $\mathrm{Mg}$ bearing) phases at elevated temperature, quantitative measurements of solute concentrations were made. Figure 3 shows the concentration of $\mathrm{Cu}$ and $\mathrm{Mg}$ in the center of the dendrite arms.
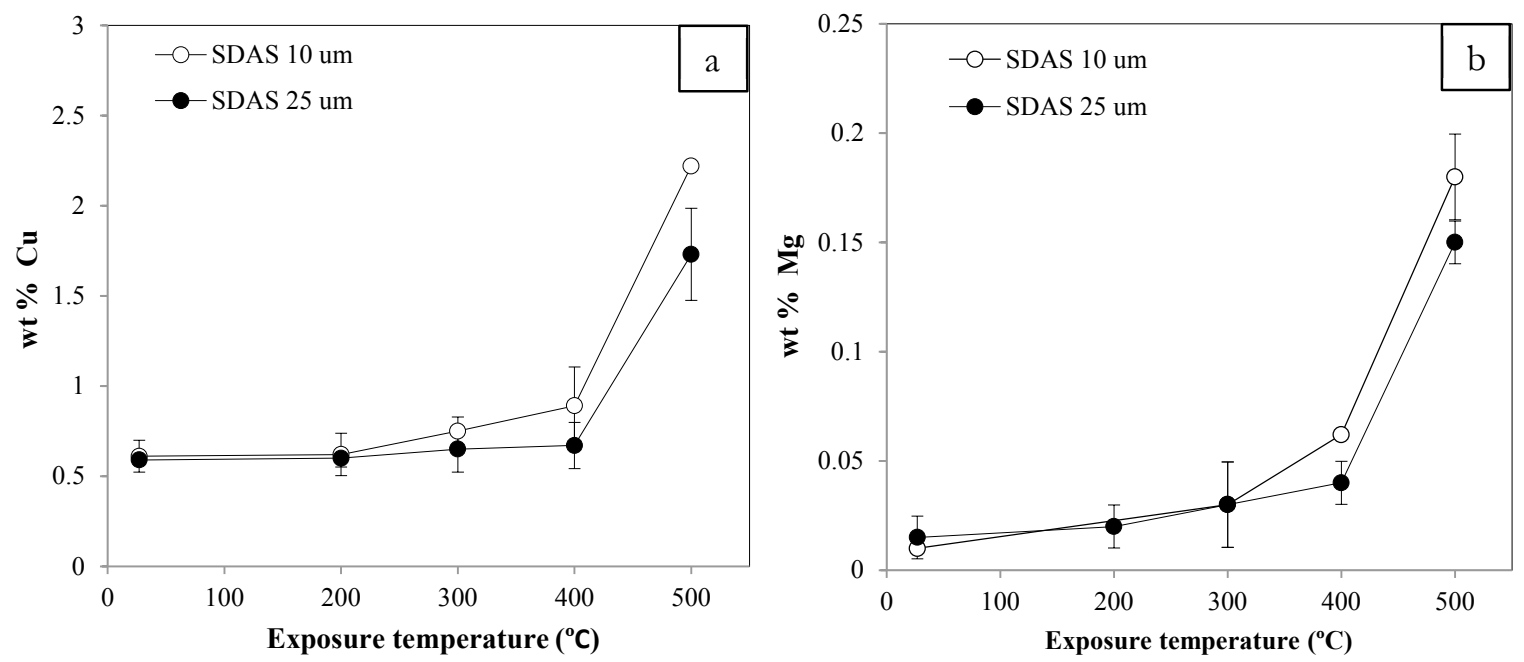

Figure 3. Solute concentration a) $\mathrm{Cu}$ and b) $\mathrm{Mg}$ at dendrite center measured after exposure to high temperature for SDAS $=10$ and $25 \mu \mathrm{m}$. The error bars, which are not applied, are just as small as the points. Error bars calculated based on $95 \%$ confidence interval. This applies to all of the figures.

The increase in $\mathrm{Cu}$ concentration in the dendrite center, illustrated in Figure 3(a) could be a consequence of dissolution of $\mathrm{Al}_{2} \mathrm{Cu}$ phase (the most abundant intermetallic) or fragmentation of other Cu-bearing phases such as $\mathrm{Q}-\mathrm{Al}_{5} \mathrm{Mg}_{8} \mathrm{Si}_{6} \mathrm{Cu}_{2}$, which is noted in other studies [7,26]. A large fraction of the $\mathrm{Al}_{2} \mathrm{Cu}$ phases in the $10 \mu \mathrm{m}$ microstructure dissolved at 500 ${ }^{\circ} \mathrm{C}$, and the solute concentration reaches $2.22 \mathrm{wt} . \%$. The blocky $\mathrm{Al}_{2} \mathrm{Cu}$ particle in the $25 \mu \mathrm{m}$ microstructure remained stable even after exposure at $500{ }^{\circ} \mathrm{C}$, suggesting a lower dissolution rate, which is consistent with the lower concentration of $\mathrm{Cu}$ (Figure $3 \mathrm{a}$ ) compared to the fine microstructure.

The Mg-richest compound, $\mathrm{Mg}_{2} \mathrm{Si}$ was rarely found in the micrographs due to the low $\mathrm{Mg}$ content in the alloy $(0.24 \mathrm{wt}$. $\%)$. Nevertheless $\mathrm{Mg}$ could be present in other intermetallic compounds such as $\pi-\left(\mathrm{Al}_{8} \mathrm{Mg}_{3} \mathrm{FeSi}_{6}\right)$. Figure 3(b) shows the $\mathrm{Mg}$ concentration in the center of the dendrite arms for both SDAS after high temperature exposure. Increased $\mathrm{Mg}$ concentration in the dendrite center for both scales of microstructure is thought to be due to dissolution of $\mathrm{Mg}_{2} \mathrm{Si}$ and also transformation of $\pi-\left(\mathrm{Al}_{8} \mathrm{Mg}_{3} \mathrm{FeSi}_{6}\right)$ to $\beta-\left(\mathrm{Al}_{5} \mathrm{FeSi}\right)$ and $\mathrm{Mg}$ in solid solution [26]. The $\mathrm{Mg}$ concentration in the fine microstructure dendrites increases from $0.015 \mathrm{wt} . \%$ in the as-cast condition to around $0.9 \mathrm{wt} . \%$ at $400{ }^{\circ} \mathrm{C}$. Figure 3 shows that dissolution of $\mathrm{Mg}$-bearing phases is more pronounced at temperatures above $400{ }^{\circ} \mathrm{C}$. In the fine microstructure, a large fraction of the available $\mathrm{Mg}$ content was transferred to the matrix in the form of a solid solution within 15 min at $500{ }^{\circ} \mathrm{C}$. The rate of $\mathrm{Mg}$ concentration increase was slower for the coarse compared to the fine microstructure as a result of slower diffusion kinetics caused by the longer diffusion distance [26]. It is therefore shown that the rate of dissolution of $\mathrm{Cu}$ - and Mg-bearing phases depends on exposure temperature and the size of those phases.

\subsubsection{Eutectic Si}

The morphology of eutectic Si particles at elevated temperature is shown Figure 2. During heating, Si particles spheroidize and then coarsen The change in Si concentration (see Figure 4) suggests a rapid spheroidization rate for fine Si particles (SDAS $10 \mu \mathrm{m}$ ) above $400{ }^{\circ} \mathrm{C}$. The coarse plate-like Si particles in the $25 \mu \mathrm{m}$ SDAS microstructure however are less responsive to spheroidization, and demand longer exposure times at a given temperature to become spheroidized. Si particles showed almost no change in their internal architecture below $300^{\circ} \mathrm{C}$. Coarse Si particles resist coarsening up to $400{ }^{\circ} \mathrm{C}$. Figure 4 shows that the $\mathrm{Si}$ concentration at the center of a dendrite arm at room temperature is lower for the fine 
microstructure rather than for the coarse one. Increasing the solidification rate reduces the time during which solid state diffusion state may take place which results in a lower concentration of Si in solid solution [27]. The marginally higher concentration of Si in the dendrite of SDAS $25 \mu \mathrm{m}$ (see Figure 4) may be due to that reason.

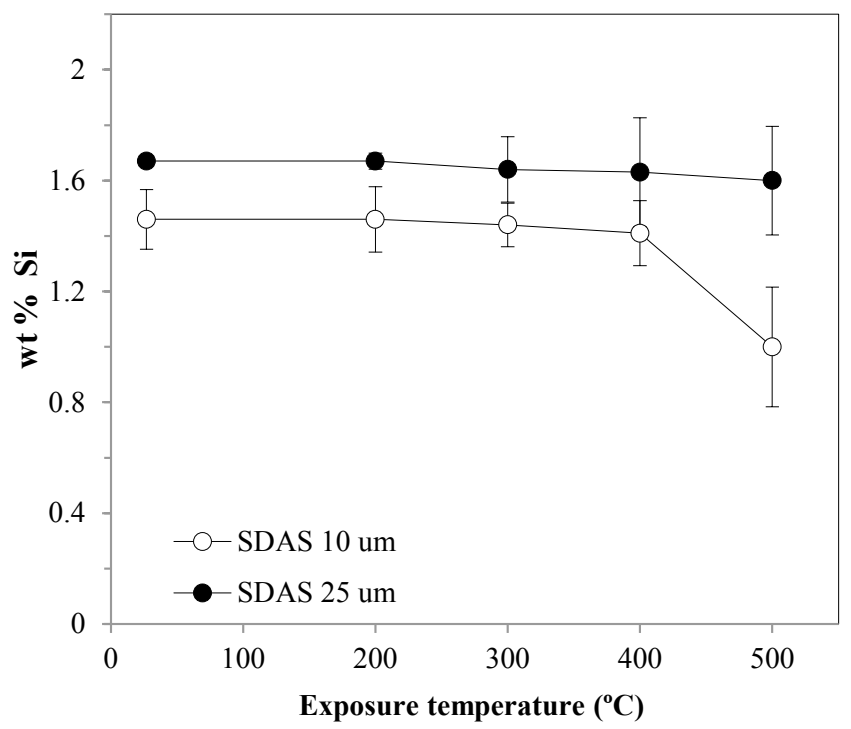

Figure 4. Si concentration in the center of dendrite arms measured after different exposure temperatures for SDAS 10 and $25 \mu \mathrm{m}$.

According to the Al-Si equilibrium phase diagram [28], Si has a maximum solid solubility in $\mathrm{Al}$ of 1.6 wt. $\%$ at $576{ }^{\circ} \mathrm{C}$, which drops to 0.8 and 0.2 wt. $\%$ at $500{ }^{\circ} \mathrm{C}$ and $400{ }^{\circ} \mathrm{C}$ respectively. Coarsening of eutectic Si as a result of increased temperature is due to diffusion-controlled reduction of $\mathrm{Si}$ in solid solution in the vicinity of the eutectic cells and migration to pure $\mathrm{Si}$ particles. The concentration of $\mathrm{Si}$ in the center of small dendrite arms (SDAS $10 \mu \mathrm{m}$ ) drops dramatically above $400{ }^{\circ} \mathrm{C}$, as $\mathrm{Si}$ is gradually depleted from solid solution and contributes to coarsening of nearby eutectic Si particles, see Figure 4. Coarse dendrite arms (SDAS $25 \mu \mathrm{m}$ ), however experienced no meaningful change in Si concentration. The larger diffusion distance in $25 \mu \mathrm{m}$ SDAS is presumed to hinder solute diffusion from the matrix to the particles; and from small to large Si particles. The spheroidization of Si by solution heat treatment is one of the steps of post-solidification processing Al-Si based cast alloys, and hence has been thoroughly discussed in that respect. Nevertheless, it is useful to note that the findings in this work are in agreement with previous studies $[26,29]$.

\subsection{Mechanical Properties}

It is well-known that casting parameters (melt cleaning, oxide films, pores etc.) have marked effects on the tensile properties of Al-Si casting alloys at room and at elevated temperatures [14]. The presence of defects is associated with significantly degraded tensile ductility which consequently shortens the plastic strain region. Such defects prevent the direct determination of stress-strain relations in the plastic region and also result in significant scattering in measured tensile properties [30]. In order to avoid this problem the levels of these defects have been minimized by using the directional solidification technique. Any effects of casting defects have therefore been neglected. Figure 5 shows the $\mathrm{R}_{\mathrm{m}}$, $\mathrm{R}_{\mathrm{p} 0.2}$ and $\varepsilon_{\mathrm{F}}$ as a function of temperature for samples with different SDAS. There is a general tendency toward decreasing $R_{m}$ and $R_{p 0.2}$ with increasing temperature due to facilitated dislocation movement [13-15, 31, 32]. The movement of dislocations through a lattice is aided by thermal vibrations. Consequently, resistance to dislocation slip increases as the temperature falls. In Al alloys, room temperature falls in a range between $0.2 \mathrm{~T}_{\mathrm{m}}$ and $0.5 \mathrm{~T}_{\mathrm{m}}$, where the deformation mechanism is usually slip [33]. Figure 5 shows that at temperatures below $300{ }^{\circ} \mathrm{C}\left(\sim 0.5 \mathrm{~T}_{\mathrm{m}}\right), \mathrm{R}_{\mathrm{m}}$ slightly decreases with increasing temperature. However at $300{ }^{\circ} \mathrm{C}$ and above the strength of the alloy degrades steeply. As the temperature increases, the potential for dislocation climb, and dislocation slip increases [33]. The fine microstructure (SDAS $10 \mu \mathrm{m}$ ) displayed superior ultimate tensile strength compared to the coarse microstructure ( $25 \mu \mathrm{m}$ SDAS) at RT. This supremacy 
was retained at temperatures up to $500{ }^{\circ} \mathrm{C}$. It was also observed that elongation to failure $\left(\varepsilon_{\mathrm{F}}\right)$ significantly increases at temperatures above $200{ }^{\circ} \mathrm{C}$ for both coarseness of microstructure. However, the fine microstructure always showed higher $\varepsilon_{\mathrm{F}}$ values at any given temperature, Figure 5, and the difference increased with increasing temperature.

The contribution of solute level on $\mathrm{R}_{0.2}$ of the alloy at room temperature has been well documented. Higher amount of solute
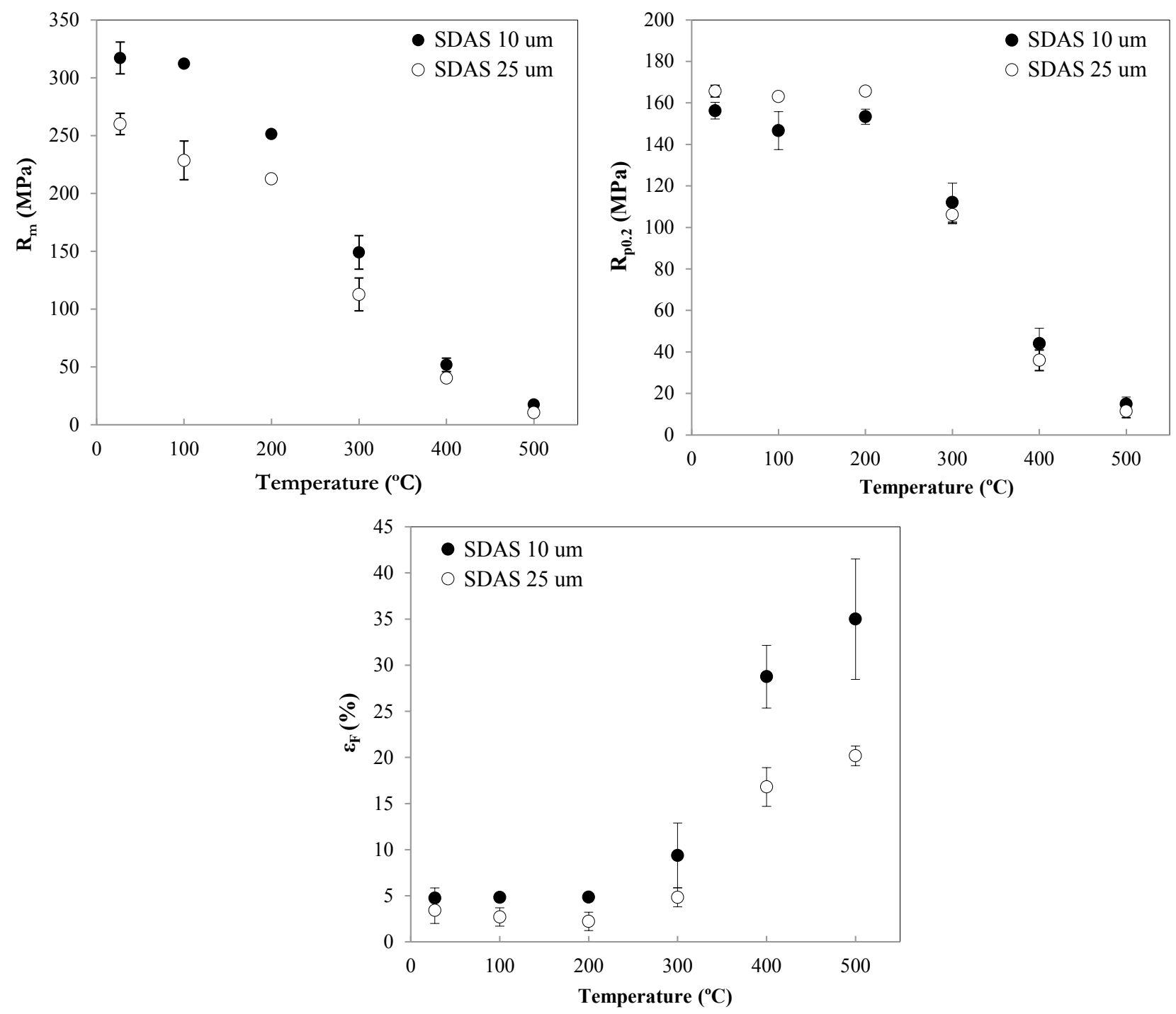

Figure 5. $\mathrm{R}_{\mathrm{m}}, \mathrm{R}_{\mathrm{p} 0.2}$ and $\varepsilon_{\mathrm{F}}$ values of EN AC-46000 alloy with different SDAS at different temperatures. Strain rate is constant and equal to $10^{-3} \mathrm{~s}^{-1}$.

results in increased yield strength in Al-Si-Cu-Mg alloys [7, 34]. It was found that $\mathrm{R}_{0.2}$ is marginally greater for the case of SDAS $25 \mu \mathrm{m}$ rather than those in SDAS $10 \mu \mathrm{m}$, see Figure 5. Olofsson et al. [2] also reported similar observations comparing SDAS 10 and $25 \mu \mathrm{m}$. Figure 3 and Figure 4 show the concentration of solutes in the coarse microstructure is slightly greater in the fine microstructure, which could explain the increase in $\mathrm{R}_{0.2}$. In other works, the aspect ratio of Si-particles [23] and size of the eutectic cell [35] were suggested to make a significant contribution to the strength of Al-Si alloys in the early strain regime $(<0.003)$. The contribution of those features however is not pronounced according to the findings of this study. Figure 5 shows that the marked difference in $\mathrm{R}_{0.2}$ fades at $300{ }^{\circ} \mathrm{C}$ and above. Neither morphology of Si-particles nor the eutectic cell size showed any indicative change up to $400{ }^{\circ} \mathrm{C}$. Nevertheless, $300{ }^{\circ} \mathrm{C}$ is the temperature where the significant 
change in solute concentration profile initiated, see Figure 3. It is therefore suggested that the yield strength is solely matrix dependent irrespective of the size of microstructural constituents.

Flow stress curves of the alloy at different temperatures for SDAS $10 \mu \mathrm{m}$ are shown in Figure 6 . This shows an increase in hardening rate at $200{ }^{\circ} \mathrm{C}$ in the low strain regime which is apparently due to precipitation hardening. A typical DSC trace for as-cast EN AC-46000 samples, scanned at a heating rate of $5{ }^{\circ} \mathrm{C} / \mathrm{min}$ showed an exothermic peak with onset temperature of 206 and $215^{\circ} \mathrm{C}$ for SDAS 10 and $25 \mu \mathrm{m}$ respectively. The peak evidently corresponds to precipitation of $\mathrm{Si}$ from supersaturated solid solution [6]. According to the equilibrium phase diagram, Si has a maximum solubility of 1.6 wt. $\%$ at $576^{\circ} \mathrm{C}$ in $\mathrm{Al}$, which is lowered to $0.26 \mathrm{wt} . \%$ at $400^{\circ} \mathrm{C}$. Results from WDS analysis indicated average concentrations of 1.45 and $1.65 \mathrm{wt} . \% \mathrm{Si}$ in the $\alpha$-Al matrix for fine and coarse microstructures respectively, Figure 4 . An initial average composition of $1.55 \mathrm{wt}$ \% supersaturated $\mathrm{Si}$ was considered as reasonable estimate in the as-cast condition. Increasing the temperature to $200^{\circ} \mathrm{C}$ results in precipitation of Si from supersaturated solid solution and a concomitant increase in strength through precipitation hardening. In a work by Rincon et al. [13], a precipitation hardening behavior was observable in the flow stress curve at $240{ }^{\circ} \mathrm{C}$ in A319 cast alloy.

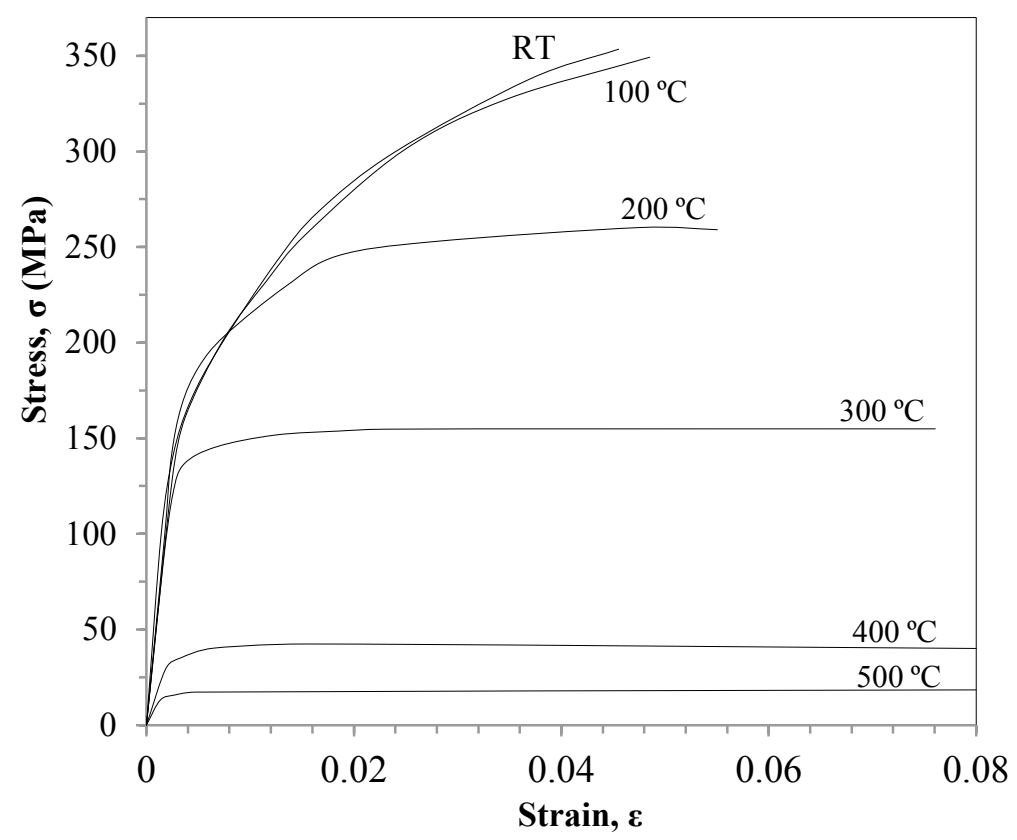

Figure 6. Flow curves corresponding to $10 \mu \mathrm{m}$ SDAS at different temperatures. SR is equal to $10^{-3} \mathrm{~s}^{-1}$.

Figure 7 shows the strain rate dependency of stress-strain behavior of the alloy at $400{ }^{\circ} \mathrm{C}$. The flow stress curves showed that the alloy became sensitive to strain rate at $300^{\circ} \mathrm{C}$ and above irrespective of coarseness of microstructure. The strain rate sensitivity $(\mathrm{SRS}=\delta \log (\sigma) / \delta \log (\mathrm{SR})$ ) at constant strain $(0.01)$ was calculated for both coarseness of microstructure. The value of $0.015 \pm 0.004$ was obtained for both SDAS 10 and $25 \mu \mathrm{m}$ at $200{ }^{\circ} \mathrm{C}$ and below. The corresponding value rises to 0.12 and 0.11 at $400{ }^{\circ} \mathrm{C}$ for the fine and coarse microstructures respectively $\left(\mathrm{R}^{2}>0.95\right)$. Both coarseness of microstructure retain rather low strain rate sensitivity even at $400{ }^{\circ} \mathrm{C}$, which is plausible due to the relatively large grain $\operatorname{size}(\sim 1-2 \mathrm{~mm})$. 


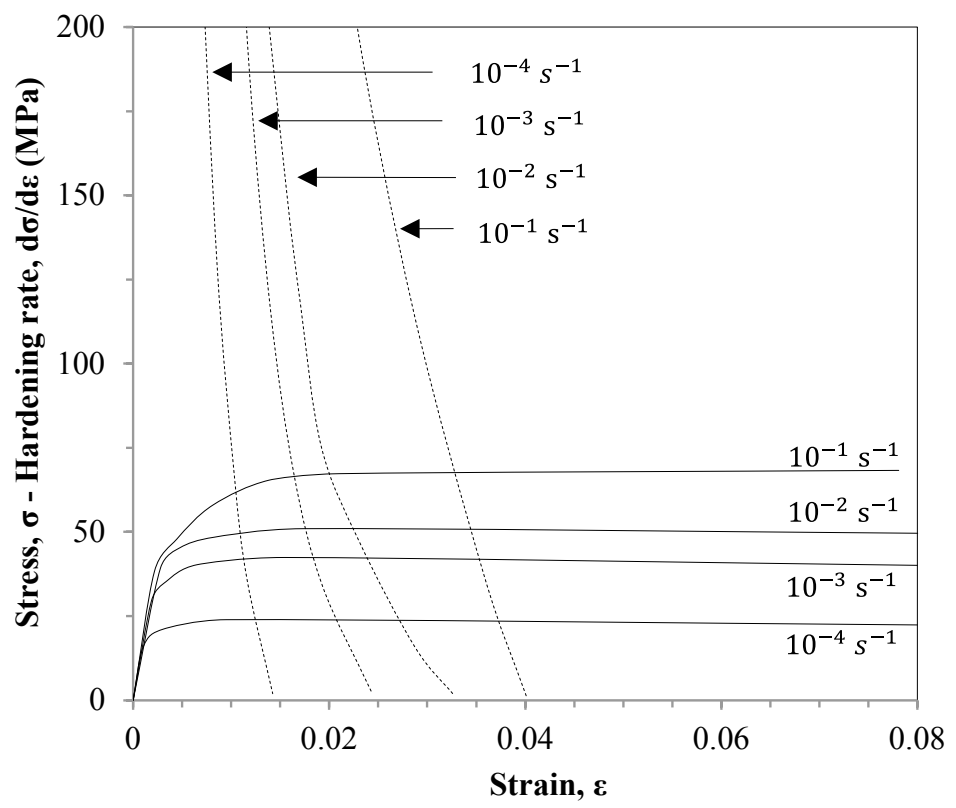

Figure 7. Flow curves corresponding to $25 \mu \mathrm{m}$ SDAS at $400{ }^{\circ} \mathrm{C}$ obtained under different SR.

An increased strain rate leads to a higher strain hardening rate at $400{ }^{\circ} \mathrm{C}$ and consequently a postponed necking occurrence. Above $0.5 \mathrm{~T}$, the dislocation density is determined by the balance between strain hardening and dynamic recovery. Once the rate of straining increases, a higher steady state dislocation density is obtained which leads to a larger saturation stress level [33]. The effect of strain rate disappears upon lowering the temperature due to the trifling rate of dynamic recovery compared to the rate of hardening.

\subsection{Deformation and fracture behavior}

As long as the level of defects (e.g. gas porosity and oxide films) in cast aluminum alloys is minimized the failure sequence consists of three consecutive steps; initiation of small damage in particles, damage growth and microcrack formation in the particles, and finally linkage of the microcracks or crack propagation $[11,30]$. The failure sequence is illustrated in Figure 8.
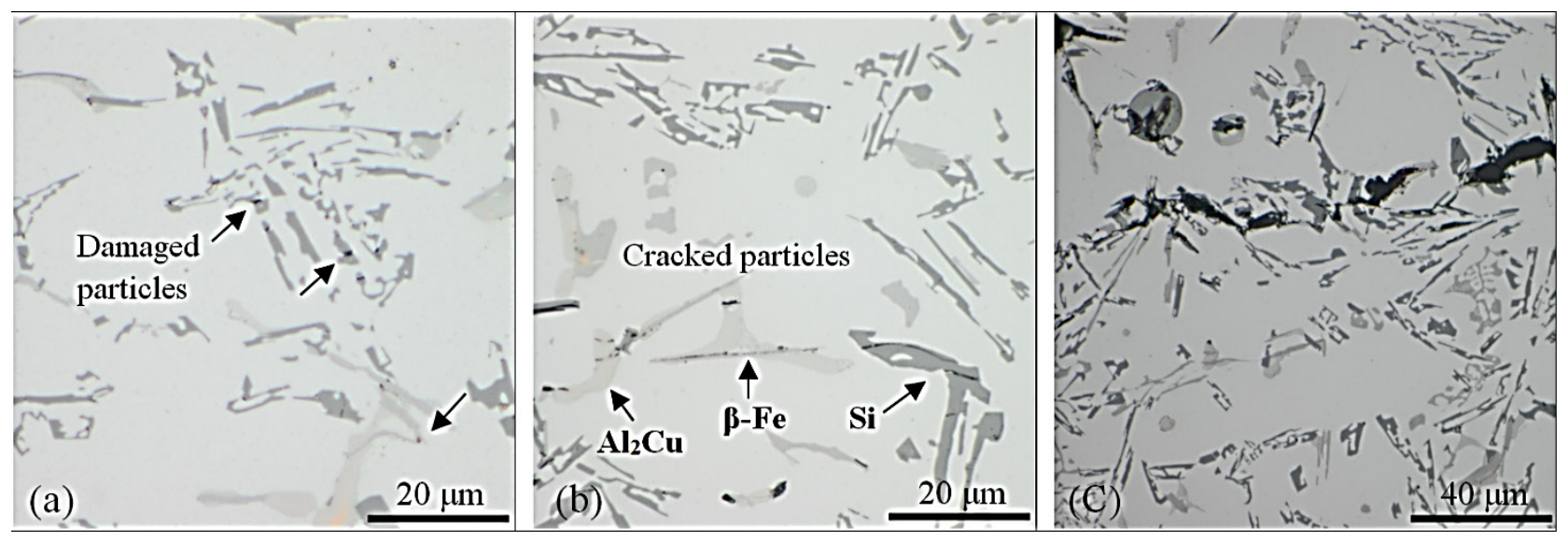

Figure 8. Micrographs showing the failure sequence. a) Damage initiation in particles, b) damage growth and c) crack linkage. SDAS $25 \mu \mathrm{m}$, test temperature $100^{\circ} \mathrm{C}, \mathrm{SR} 10^{-4} \mathrm{~s}^{-1}$. The tensile axis is horizontal in all images.

In order to assess the role of microstructure coarseness, temperature and strain rate on the failure mechanism, the damage frequency (ratio of damaged/cracked particles over all particles) and area fraction of damaged/cracked particles in failed specimens was quantitatively measured using image analysis. Measurements were made at room temperature in the central 
plane over the entire gauge length. Micrographs showed that the majority of cracked particles at any given condition were found in the region close to the fracture surface. Hence, the measurement in that region only was taken into account. Figure 9 shows the fraction of cracked particles as a function of temperature for the fine and coarse microstructures.

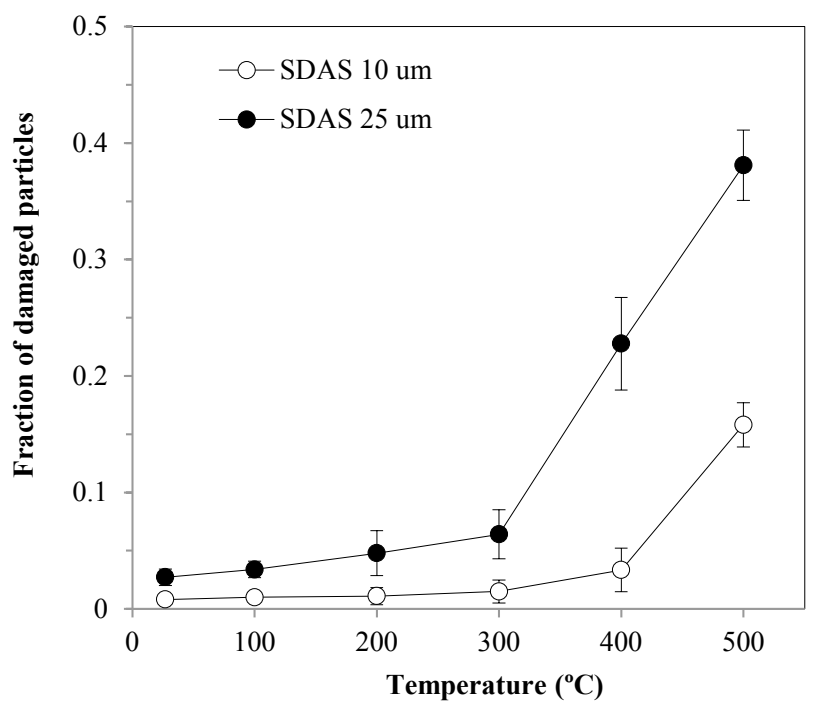

Figure 9. Fraction of damaged particles as of function of tensile test temperature.

It is evident that in the coarse microstructure increasing temperature leads to a monotonic increase in fraction of damaged particles, and the increase becomes significant above $300{ }^{\circ} \mathrm{C}$. In the fine microstructure however, the fraction of damaged particles below $300{ }^{\circ} \mathrm{C}$ was quite limited (fraction lower than 0.02 ) and at $400{ }^{\circ} \mathrm{C}$ and beyond, the fraction increased significantly. Plastic flow of the alloy is governed by stress incompatibilities between plastically deformed matrix and elastically strained particles. Once plastic strain in the alloy starts, the brittle second phase particles begin to form microcracks. This continues until a critical strain in which a critical volume fraction of cracked particles is reached, which leads to micro crack coalescence and failure as the matrix between the fractured particles becomes unstable. The process is primarily controlled by microstructure and matrix-properties [11,31]. As long as the mode of fracture is brittle (below $300{ }^{\circ} \mathrm{C}$ ) particles dominate the microcracks linking process. As the matrix softens at higher temperatures, the matrix properties begin to play a role in the failure process. Raising the temperature may reduce the matrix instability between the fractured particles and microcracks. On the other hand, the stress induced in particles during matrix deformation will be intensified which leads to further particle damage and void formation. The end result is an increased fraction of fractured particles and increased strain. This trend was clearly seen in the coarse microstructure of this study (SDAS $25 \mu \mathrm{m}$ in Figure 9). Rincon et al. [13] reported that increasing the temperature from $250{ }^{\circ} \mathrm{C}$ to $400{ }^{\circ} \mathrm{C}$ leads to an increase in fraction of cracked particles from $12 \%$ to $50 \%$ in an Al8Si3CuMg cast alloy having SDAS in the range 24-36 $\mu \mathrm{m}$, which is in agreement with the findings of this work. Mahidhara \& Mukherjee [31] also reported that as eutectic Si particles in a AlSi eutectic alloy become coarser, the level of cavitation at the matrix-Si particle interface was significantly increased at $558^{\circ} \mathrm{C}$.

Inter-particle cracking is a function of size, aspect ratio and type of particles as well their orientation with respect to the direction of applied load. Since larger defects and voids are allowed to exist in larger particles, they have a lower fracture stress and in turn they fracture promptly, as suggested by Wang et al and Hunt [12, 36]. In the microstructure with SDAS $25 \mu \mathrm{m}$, damage initiates more readily in elongated particles rather than in particles having a smaller aspect ratio. Particles in the fine microstructure (SDAS $10 \mu \mathrm{m}$ ) were however less prone to damage, as they have a smaller and less scattered aspect ratio, see Table 1. This is supported by the fact that higher aspect ratio particles accumulate stress at a faster rate and accordingly tend to crack earlier, as suggested by Wang [23]. It was observed that the fraction of damaged $\mathrm{Al}_{2} \mathrm{Cu}$ and $\beta-\mathrm{Al}_{5} \mathrm{FeSi}$ particles was higher than the fraction of damaged Si particles. This was also noticed in another study [13]. However, in the present study no quantitative measurement was done to distinguish secondary particles according to type. 
Figure 10 shows SEM micrographs of the fracture surface of the two microstructures which were strained to failure at room temperature, 300 and $400{ }^{\circ} \mathrm{C}$. It is obvious that the coarse microstructure experienced brittle fracture at $300{ }^{\circ} \mathrm{C}$ and below due to the presence of large plate-like brittle phases. Rapid fracture of coarse particles and intergranular propagation of microcracks shield the matrix from plastic deformation (Figure $10 \mathrm{~d}$ and e). Lack of plasticity $(<5 \%)$ suggests that the cast alloy with SDAS $25 \mu \mathrm{m}$ is intrinsically brittle below $300^{\circ} \mathrm{C}$.

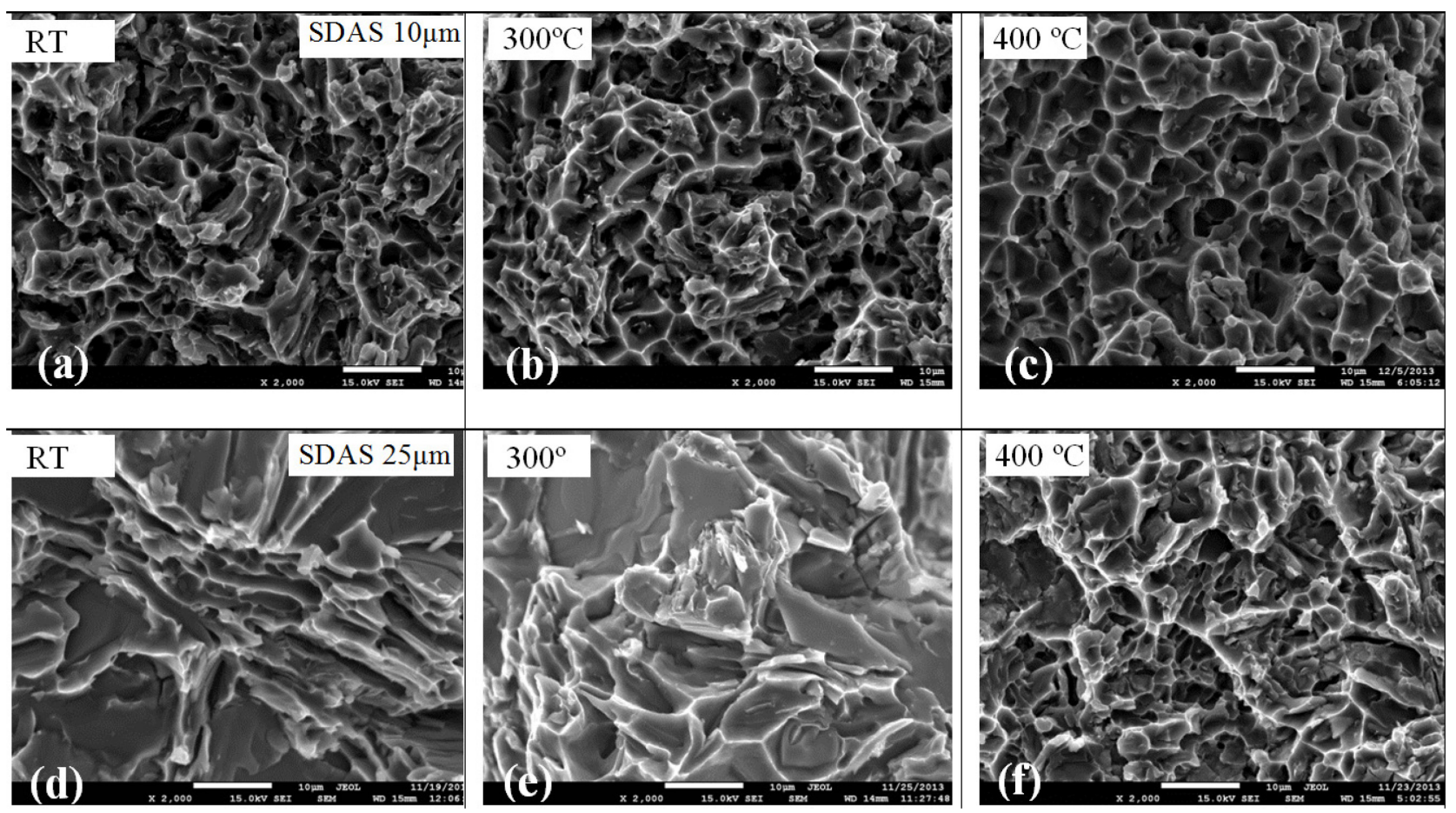

Figure 10. SEM micrographs of fractured surfaces of the alloy with SDAS 10 and $25 \mu \mathrm{m}$ tested at different temperatures. $\mathrm{SR}$ is equal to $10^{-3} \mathrm{~s}^{-1}$.

Figure 11 shows the tensile instability behavior of the alloy with fine and coarse microstructure at temperatures of $200{ }^{\circ} \mathrm{C}$ and $300{ }^{\circ} \mathrm{C}$. Below $200{ }^{\circ} \mathrm{C}$, the derivative of the curves does not meet the flow curves of the fine microstructure suggesting that brittle failure occurred at this temperature. The accumulation of damage in particles leading to failure takes place prior to necking. At $200{ }^{\circ} \mathrm{C}$ and above however, the instability criterion is met, indicating that $200{ }^{\circ} \mathrm{C}$ marks the brittle to ductile failure transition temperature. In the coarse microstructure, the instability criterion is satisfied at $300^{\circ} \mathrm{C}$, see Figure 11 . At $400{ }^{\circ} \mathrm{C}$ the coarse microstructure shows the typical dimples of ductile fracture and multiple cracked particles in the fracture surface. In contrast, the fracture surface of the fine microstructure tested at room temperature contains ductile dimples, see Figure 10a. The number of dimples was significantly increased at $300^{\circ} \mathrm{C}$, proving the fully ductile fracture above $200{ }^{\circ} \mathrm{C}$, which is a consistent finding based on instability criteria. In a similar study to this [14], it was found that A319 alloy softens in the interval of 270 to $320^{\circ} \mathrm{C}$, where SDAS ranged from 20-50 $\mu$ m which agrees well the results for the case of SDAS $25 \mu \mathrm{m}$. 


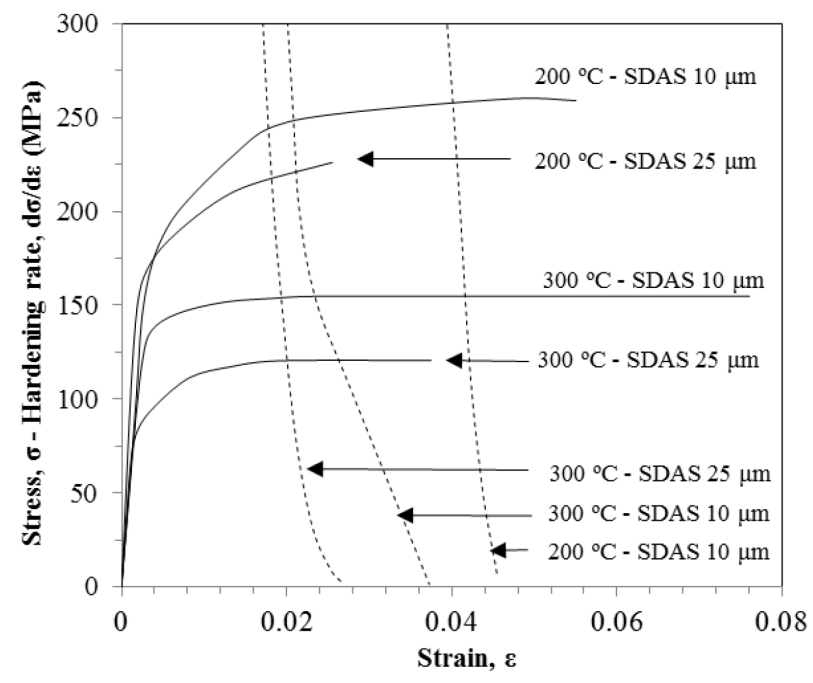

Figure 11. Tensile instability plots of the alloy at 200 and $300^{\circ} \mathrm{C}$; for SDAS 10 and $25 \mu \mathrm{m}$. SR is equal to $10^{-3} \mathrm{~s}^{-1}$.

In a study by Wang [23] it is suggested that in alloys with large SDAS, the failure occurs prior to necking at RT as a result of the high damage accumulation rate caused by particle cracking. In small SDAS samples however, necking takes place below the fracture strain. The comparison was made between 17 and $54 \mu \mathrm{m}$ SDAS in A356/357 alloy. It is therefore feasible that in the coarse microstructure damaged particles $\left(\mathrm{Si}, \mathrm{Al}_{2} \mathrm{Cu}\right.$ and $\beta-\mathrm{Al}_{5} \mathrm{FeSi}$ etc.) cause premature failure but that this is deferred to a higher temperature $\left(300^{\circ} \mathrm{C}\right)$ when necking occurs due to increase matrix plasticity. In the fine microstructure however, post-necking damage through particle cracking apparently takes place at $200^{\circ} \mathrm{C}$. Results of tensile instability in the fine microstructure do not agree with the suggestion by Wang [23]. This contradiction may be due to the higher level of $\mathrm{Si}(10 \mathrm{wt} . \%)$ and the presence of $\mathrm{Cu}(2.6 \mathrm{wt}$. \%) in the EN AC-46000 alloy, which limits the intrinsic ductility of the matrix. The tensile instability point of the fine and coarse microstructure approaches the same value at higher temperature (above $400{ }^{\circ} \mathrm{C}$ ), indicating that necking occurrence is determined by stress relaxation during plastic deformation instead of damage accumulation in particles [14]. Two typical modes of damage accumulation found in the present study are single micro cracks and microcrack clusters, see Figure 12 (c) and (d).
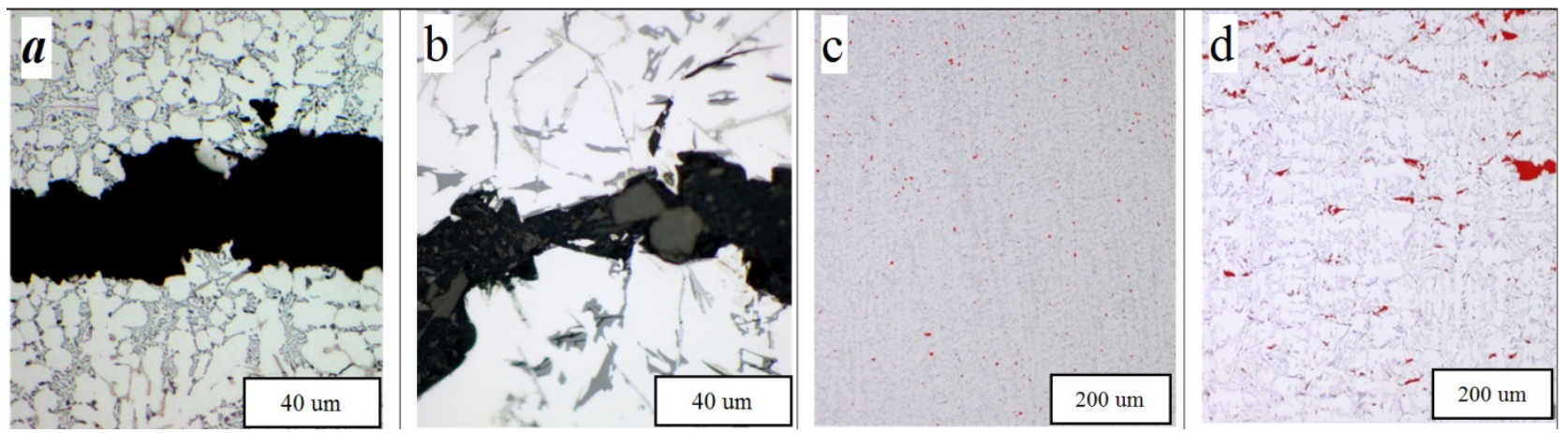

Figure 12. Optical micrographs showing fracture path of failed specimen a) SDAS $10 \mu \mathrm{m}, \mathrm{RT}, 10^{-2} \mathrm{~s}^{-1}$, b) SDAS 10 $\mu \mathrm{m}, \mathrm{RT}, 10^{-2} \mathrm{~s}^{-1} ; \mathrm{c}$ ) single microcrack and d) microcracks clusters at RT, $10^{-2} \mathrm{~s}^{-1}$.

It has been proposed that the rate of damage formation in single particles at different strain is approximately constant. The accumulation of damage in particles however is rare at low strain levels and becomes significant as the fracture strain is approached [36]. Figure 13 shows the area fraction of fractured particles and cavities as a function of strain rate at $500{ }^{\circ} \mathrm{C}$ for different microstructure coarseness. 


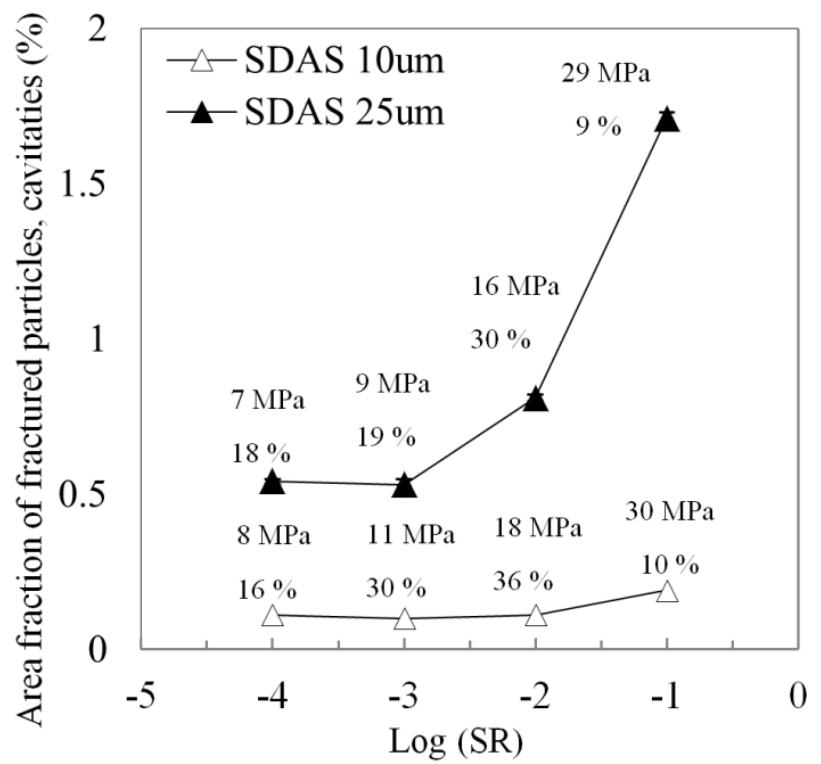

Figure 13. 2D Area fraction of fractured particles and cavities at particle/matrix interface as function of strain rate at $500{ }^{\circ} \mathrm{C}$. The corresponding elongation to failure and $\mathrm{R}_{\mathrm{m}}$ are indicated for each case.

It was observed that at $500{ }^{\circ} \mathrm{C}$ increasing the strain rate from $10^{-3}$ to $10^{-1} \mathrm{~s}^{-1}$ profoundly increased the area fraction of fractured particles for the coarse microstructure. The trend was not as clear at $400{ }^{\circ} \mathrm{C}$ and no trend was found at lower temperature, nor was this trend evident for the fine microstructure. This suggests that the cleaving rate of the particles which are already fractured at lower strain levels is related to a thermally activated stress relaxation mechanism such as dislocation climb. Increasing the strain rate leads to a higher dislocation density [33] and accordingly an increased number of dislocations enhances the probability of interactions with particles. Micrographs suggest that an increase in the area fraction of damaged particles includes more frequent microcrack clusters and single cleaved particles. However, no meaningful trend was observed between the strain rate and elongation to failure at $500{ }^{\circ} \mathrm{C}$ (see Figure 13) or any other test temperatures. This is consistent with somewhat lower ductility of the alloy at higher strain rate (due to the increased probability of microcrack aggregation). The higher strain rate leads to instability in plastic deformation at higher strength and strain at elevated temperature (above $400{ }^{\circ} \mathrm{C}$ ) see Figure 7. Extended local uniform plastic strain at high strain rates resulted in opening of microcracks and shattering of cracked particles without any pronounced initiation of damage in the particles. Localized shear bands formed in the matrix at the edge of microcracks (mostly inside the grains) provide an opportunity for fractured particles to grow [11]. Mahidhara \& Mukherjee [31] report quite the opposite observation for an $\mathrm{Al}-13 \mathrm{Si}$ wrought alloy deformed at $557^{\circ} \mathrm{C}$ under different strain rates. It was qualitatively observed that by reducing the strain rate from $10^{-2}$ to $10^{-5} \mathrm{~s}^{-1}$, the numbers of cavities - particularly in grain boundaries - surprisingly increased and elongation to failure monotonically decreased. Their observation is however not consistent with the findings of the current study. Unlike the Al-13Si wrought alloy [31] in which the grain size ranged from 15-35 $\mu \mathrm{m}$, grain boundary sliding is not a plausible deformation mechanism in the EN AC-46000 alloy which has a grain size of around 1-2 $\mathrm{mm}$. Therefore, the higher rate of straining does not necessarily facilitate grain boundary sliding and consequently improved plasticity. Another reason which may be relevant is the inevitable uncertainties related to the mode of processing (e.g. casting defects). Since the samples are in the as-cast condition, their plasticity severely suffers from such defects. 


\section{Conclusions}

The tensile properties and deformation behavior of EN AC-46000 alloy in the temperature range of room to $500{ }^{\circ} \mathrm{C}$ were studied. The microstructure comprised two distinctive coarseness, a) SDAS $10 \mu \mathrm{m}$ and b) SDAS $25 \mu \mathrm{m}$. The strain rate during tensile testing was varied from $10^{-4} \mathrm{~s}^{-1}$ to $10^{-1} \mathrm{~s}^{-1}$.

1- $\mathrm{R}_{\mathrm{m}}, \mathrm{R}_{\mathrm{p} 0.2}$, and $\varepsilon_{\mathrm{F}}$ were largely dependent on temperature. Ductility increased surprisingly above $300{ }^{\circ} \mathrm{C}$, even for the case of coarse microstructure. $\mathrm{R}_{\mathrm{p} 0.2}$ showed no significant decrease from ambient temperature to $200^{\circ} \mathrm{C}$, however above that it decreased monotonically. $\mathrm{R}_{\mathrm{m}}$ consistently decreased with increasing temperature for the case of SDAS 10 and 25 $\mu \mathrm{m}$.

2- The strain rate effects on tensile behavior were not significant below $20{ }^{\circ} \mathrm{C}$ for both SDAS 10 and $25 \mu \mathrm{m}$. The effect of strain rate became more important at $300{ }^{\circ} \mathrm{C}$ where the flow stress of the alloy decreased dramatically. At this temperature and above, strain rate has a marked effect on $\mathrm{R}_{\mathrm{m}}$. The effect on the flow stress curve became even more highlighted at $400^{\circ} \mathrm{C}$ and above. Four order of magnitude increase in strain rate at $500^{\circ} \mathrm{C}$ (from $10^{-4}$ to $10^{-1} \mathrm{~s}^{-1}$ ) resulted in a higher flow stress, even when the temperature was $100^{\circ} \mathrm{C}$ lower $\left(10^{-4} \mathrm{~s}^{-1}\right.$ at $\left.400{ }^{\circ} \mathrm{C}\right)$.

3- The concentration of $\mathrm{Cu}$ and $\mathrm{Mg}$ in the dendrites increases as the temperature exceeds $300{ }^{\circ} \mathrm{C}$. The increase becomes significant above $400{ }^{\circ} \mathrm{C}$. The rate of dissolution of $\mathrm{Mg}$ - and Cu-bearing phases is higher in the alloy with fine microstructure. Spheroidazation of eutectic silicon particles occurred above $400{ }^{\circ} \mathrm{C}$ and the rate was greater in the fine microstructure alloy.

4- The brittleness of the alloy below $300{ }^{\circ} \mathrm{C}$ was related to accumulation of a high volume fraction damaged particles such as $\mathrm{Cu}$ - Fe-bearing phases and Si-particles. The initiation rate of damage in the coarse particles was significantly higher, which enhances the probability of failure and decreasing both $R_{m}$ and $\varepsilon_{\mathrm{F}}$ compared to the fine microstructure.

5- The fraction of cracked particles was found to be a function of temperature. The coarse microstructure is more sensitive to crack formation at any given temperature. The area fraction of damaged particles was significantly increased at high strain rate $\left(10^{-1} \mathrm{~s}^{-1}\right)$ at $500{ }^{\circ} \mathrm{C}$. No meaningful relation between the fraction of damaged particles and strain rate was found at any temperature.

\section{Acknowledgments}

This research was supported by the KK-foundation in Sweden and Kongsberg Automotive AB as a part of the CompCAST program.

\section{References}

1. Wang, L., M. Makhlouf, and D. Apelian, Aluminium die casting alloys: alloy composition, microstructure, and properties-performance relationships. International Materials Reviews, 1995. 40(6): p. 221-238.

2. Olofsson, J., I.L. Svensson, P. Lava, and D. Debruyne, Characterisation and investigation of local variations in mechanical behaviour in cast aluminium using gradient solidification, Digital Image Correlation and finite element simulation. Materials \& Design, 2014. 56: p. 755-762.

3. Stevenson, M.L.W.a.M.E., Introduction to the Mechanical Behavior of Nonmetallic Materials, Mechanical Testing and Evaluation. ASM Handbook, ASM International, 2000. 8: p. 13-25.

4. Committee, A.I.H., D.U. Furrer, and S. Semiatin, Fundamentals of Modeling for Metals Processing. Vol. 22A. 2009: ASM International.

5. McClintock, F.A. and A.S. Argon, Mechanical behavior of materials. Vol. 277. 1966: Addison-Wesley Reading, MA.

6. Li, R., R. Li, Y. Zhao, L. He, C. Li, H. Guan, and Z. Hu, Age-hardening behavior of cast Al-Si base alloy. Materials letters, 2004. 58(15): p. 2096-2101.

7. Sjölander, E. and S. Seifeddine, The heat treatment of $\mathrm{Al}-\mathrm{Si}-\mathrm{Cu}-\mathrm{Mg}$ casting alloys. Journal of Materials Processing Technology, 2010. 210(10): p. 1249-1259. 
8. Johnson, G.R. and W.H. Cook. A constitutive model and data for metals subjected to large strains, high strain rates and high temperatures. in Proceedings of the 7th International Symposium on Ballistics. 1983. The Hague, Netherlands: International Ballistics Committee.

9. Martínez D, E.J., M.A. Cisneros G, S. Valtierra, and J. Lacaze, Effect of strontium and cooling rate upon eutectic temperatures of A319 aluminum alloy. Scripta Materialia, 2005. 52(6): p. 439-443.

10. Zamani, M., S. Seifeddine, and M. Aziziderouei. The role of Sr on microstructure formation and mechanical properties of $\mathrm{Al}-\mathrm{Si}-\mathrm{Cu}-\mathrm{Mg}$ cast alloy. 2013.

11. Wang, Q., Microstructural effects on the tensile and fracture behavior of aluminum casting alloys A356/357. Metallurgical and Materials Transactions A, 2003. 34(12): p. 2887-2899.

12. Wang, Q., C. Caceres, and J. Griffiths, Damage by eutectic particle cracking in aluminum casting alloys A356/357. Metallurgical and Materials Transactions A, 2003. 34(12): p. 2901-2912.

13. Rincón, E., H. López, M. Cisneros, H. Mancha, and M. Cisneros, Effect of temperature on the tensile properties of an as-cast aluminum alloy A319. Materials Science and Engineering: A, 2007. 452: p. 682-687.

14. Rincon, E., H. Lopez, M. Cisneros, and H. Mancha, Temperature effects on the tensile properties of cast and heat treated aluminum alloy A319. Materials Science and Engineering: A, 2009. 519(1): p. 128-140.

15. Mohamed, A. and F. Samuel, Microstructure, Tensile Properties and Fracture Behavior of High Temperature Al-Si-Mg-Cu Cast alloys. Materials Science and Engineering: A, 2013.

16. Stadler, F., H. Antrekowitsch, W. Fragner, H. Kaufmann, and P. Uggowitzer, Effect of main alloying elements on strength of Al-Si foundry alloys at elevated temperatures. International Journal of Cast Metals Research, 2012. 25(4): p. 215-224.

17. Hernandez-Sandoval, J., G. Garza-Elizondo, A. Samuel, S. Valtiierra, and F. Samuel, The ambient and high temperature deformation behavior of $\mathrm{Al}-\mathrm{Si}-\mathrm{Cu}-\mathrm{Mg}$ alloy with minor Ti, $\mathrm{Zr}$, Ni additions. Materials \& Design, 2014. 58: p. 89-101.

18. Shaha, S., F. Czerwinski, W. Kasprzak, and D. Chen, Tensile and compressive deformation behavior of the $\mathrm{Al}-\mathrm{Si}-\mathrm{Cu}-\mathrm{Mg}$ cast alloy with additions of $\mathrm{Zr}, \mathrm{V}$ and Ti. Materials \& Design, 2014. 59: p. 352-358.

19. Stadler, F., H. Antrekowitsch, W. Fragner, H. Kaufmann, and P.J. Uggowitzer, The effect of Ni on the hightemperature strength of Al-Si cast alloys, 2011. p. 274-277.

20. Wang, E., X. Hui, and G. Chen, Eutectic Al-Si-Cu-Fe-Mn alloys with enhanced mechanical properties at room and elevated temperature. Materials \& Design, 2011.32(8): p. 4333-4340.

21. Asghar, Z., G. Requena, and F. Kubel, The role of Ni and Fe aluminides on the elevated temperature strength of an AlSi12 alloy. Materials Science and Engineering: A, 2010. 527(21): p. 5691-5698.

22. Standard Methods of Tension Testing Wrought and Cast Aluminum and Magnesium Alloy Products. ASTM B557M-10. Annual Book of ASTM Standards. American Society for testing and Materials 2010.

23. Wang, Q., Plastic deformation behavior of aluminum casting alloys A356/357. Metallurgical and Materials Transactions A, 2004. 35(9): p. 2707-2718.

24. Seifeddine, S., T. Sjögren, and I.L. Svensson, Variations in microstructure and mechanical properties of cast aluminium EN AC 43100 alloy. the Journal of Metallurgical Science \& Technology, 2007. 25(1): p. 12-22.

25. Han, Y., A. Samuel, F. Samuel, S. Valtierra, and H. Doty, Effect of Solution Heat Treatment Type on the Dissolution of Copper Phases in Al-Si-Cu-Mg Type Alloys. Transactions of the American Foundrymen's Society, 2008. 116: p. 79.

26. Sjölander, E. and S. Seifeddine, Optimization of Solution Treatment of Cast Al-7Si-0.3 Mg and Al-8Si-3Cu$0.5 \mathrm{Mg}$ Alloys. Metallurgical and Materials Transactions A, 2011: p. 1-12.

27. Dons, A., L. Pedersen, and L. Arnberg, The origin of 'anomalous' microsegregation in Al-Si foundry alloys - modelling and experimental verification. Materials Science and Engineering: A, 1999. 271(1): p. 91 94.

28. Mondolfo, L.F., Aluminum alloys: structure and properties2013: Elsevier.

29. Apelian, D., S. Shivkumar, and G. Sigworth, Fundamental aspects of heat treatment of cast Al-Si-Mg alloys. AFS transactions, 1989. 97: p. 727-742.

30. Zamani, M., S. Seifeddine, and A. EW Jarfors. Effects of Microstructure and Defects on Tensile and Fracture Behaviour of a HPDC Component; Potential Properties and Actual Outcome of En AC-44300 Alloy. in Light Metals 2014. 2014.

31. Mahidhara, R. and A. Mukherjee, High temperature flow and failure processes in an Al-13 wt\% Si eutectic alloy. Journal of Materials Science, 1997. 32(3): p. 809-814.

32. Garza-Delgado, A., K. Kabiri-Bamoradian, and R.A. Miller, Determination of Elevated-Temperature Mechanical Properties of an Aluminum A380.0 Die Casting Alloy in the As-Cast Condition. Die Casting Engineer, 2008. 52(6): p. 40-46. 
33. Stouffer, D.C. and L.T. Dame, Inelastic deformation of metals: models, mechanical properties, and metallurgy 1996: John Wiley \& Sons.

34. Cáceres, C., J. Sokolowski, and P. Gallo, Effect of ageing and $\mathrm{Mg}$ content on the quality index of two model Al $\square \mathrm{Cu} \square \mathrm{Si} \square \mathrm{Mg}$ alloys. Materials Science and Engineering: A, 1999. 271(1): p. 53-61.

35. Benzerga, A.A., S.S. Hong, K.S. Kim, A. Needleman, and E. Van der Giessen, Smaller is softer: an inverse size effect in a cast aluminum alloy. Acta Materialia, 2001. 49(15): p. 3071-3083.

36. Hunt Jr, W., J. Brockenbrough, and P. Magnusen, An Al-Si-Mg composite model system: microstructural effects on deformation and damage evolution. Scripta metallurgica et materialia, 1991. 25(1): p. 15-20. 